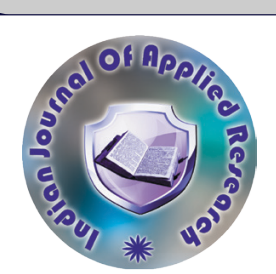

Orthopaedics

\title{
EVALUATION OF SURGICAL MANAGEMENT OF SPONDYLOLISTHESIS \\ IN LUMBAR SPINE WITH PEDICLE SCREW ROD FIXATION AND POSTEROLATERAL FUSION- A OBSERVATIONAL STUDY
}

\section{Dr. L. Kiran Kumar*}

\section{G. Ramakrishna}

\section{Dr. K. Ramakrishna}

Associate Professor, Department of Orthopaedics, Government Medical College \& GGH, Suryapet, Telangana, India. *Corresponding Author

Assistant Professor, Department of Orthopaedics, Osmania Medical College \& OGH, Hyderabad, Telangana, India.

Assistant Professor, Department of Orthopaedics, Government Medical College \& GGH, Suryapet, Telangana, India.

ABSTRACT BACKGROUND: Incidence of spondylolisthesis in general population is 5\% - 7\%. No matter what the etiology is, patients usually have significant functional disability. Few studies have investigated the long term effect of posterolateral fusion on functional outcome. OBJECTIVE: To assess the corrections of slip angle and meyerding grading after application of pedicle screw fixation and finally observed the neurological outcome \& complications of the instrumentation and its efficacy. METHODOLOGY: It's a Cross sectional observational study. On an average 20 cases of spondylolisthesis are admitted in Gandhi Hospital in a year. 20 patients were admitted to this hospital. Among these 20 cases 12 cases were selected for pedicle screw fixation and posterolateral fusion. The material for this study was selected from the initial 12 out of 20 cases where we performed pedicle screw fixation and posterolateral fusion for spondylolisthesis treatment during the period of 2008-2010. RESULTS: In our study, we have cases with age ranging from 35-60 yrs. The average age of presentation in 45 yrs. Postoperatively we had 6 cases of grade 2 with return to grade one and 2 cases remained grade 2 and 3 cases with grade 1 remained grade 1 with reduced displacement. One case of grade 3 return to grade 2. In our study, we had patients slip angles ranging from $10-50 \mathrm{o}$ with 8 cases having slip angles from 25-50o and 3 cases having slip angles from 10-30o and case had 55 o slip angle initially. In our study we had $10 \%$ neurological defects post operatively. CONCLUSION: Posteriolateral fusion is still a safe, promising and appealing technique.

KEYWORDS : Spondylolisthesis, Posterolateral Fusion, Functional Outcome

\section{INTRODUCTION}

Care of patients with spondylolisthesis with or without neurologic defects has evolved dramatically over the past 30 years with the emergence of more effective spinal instrumentation and anaesthesia techniques. Despite these advances the majority of the patients spondylolisthesis are treated non / of operatively with physiotherapy lumbar brace and NSAIDS. ${ }^{1-4}$ More aggressive treatment is guided by the use of classification systems the detail mechanism of with spondylolisthesis, the degree of slippage of vertebra, and the potential for late mechanical instability or neurological defect the goal of treatment remains attainment of spinal stability with protection or improvement of the patient's neurological status, allowing rapid and maximal functional recovery. ${ }^{5,6}$

The advent of improved anaesthetic management, the introduction of image intensifier helped the orthopaedic surgeons greatly in the management of spondylolisthesis. Modern techniques of segemental instrumentations with pedicle screws have clear advantages over distractions constructs and luque rods or rectangles, which are reported to worsen the conditions. ${ }^{7,8}$ Earlier surgical methods like posterior in situ fusion and posterior decompression have given way to the more surgeon's friendly instrumentations with pedicle rod screw fixation and postero lateral fusion system. The system by reducing the displaced vertebra has helped the early relief of neurological symptoms and deficit recovery preventing further progression and more risky surgeries."

OFF late we are receiving more number of these patients mostly with backache and seiatica with or without neurological deficits. A special spinal ward is created in the new premises of the Gandhi hospital secunderabad. The government of Andhrapradesh is providing the instrumentation free of cost it's through various schemes to the poor and needy.

We underlook this study in Gandhi Hospital from 2008-2010 in our patients who underwent surgery with this latest instrumentations.

\section{Aim of the study}

1. To assess the corrections of slip angle and meyerding grading after application of pedicle screw fixation

2. To study the fusion rate and stability in the followup period in postlateral fusion in spondylilisthesis

3. To study the neurological outcome at the end of the study period
4. To study the complications of the instrumentation and its efficacy.

\section{MATERIALS AND METHODS \\ Materials}

On an average 20 cases of spondyolisthesis are admitted in Gandhi Hospital in a year. In 2008-2010. 20 patients were admitted to this hospital. Among these 20 cases 12 cases were selected for pedicle screw fixation and posterolateral fusion. The material for this study was selected from the initial 12 out of 20 cases where we performed pedicle screw fixation and posterolateral fusion for spondylolisthesis treatment during the period of 2008-2010. All the cases were followed up 1 year. Initial evolution includes a detailed history, clinical examination and important investigations which included haematological, radiological and neurological studies. The cases were initially subjected in all referrals like physician, general surgery to rule out other diseases.

\section{Each case was studied in the following protocol}

Detailed history

General examination

Neurological examination

Investigations

Treatment pedicle screw rod fixation and posteolateral fusion Periodical follow-up

\section{Follow-up evaluation and results}

The minimum follow-up period was 6 months while the longest period was 2 years. With an average of 6 months and while the longest period was 24 months with average of 16 months. The clinical evaluation includes symptomatic relief, neurological improvement, spinal deformity and return to work. Radiological evaluation includes correction of slip angles, and meyerding grading.

\author{
Investigations done for present study \\ Haematological \\ Haemoglobin \\ Complete blood picture \\ Clotting time \\ Bleeding time \\ Plate late count \\ Erythrocyte sedimentation rate \\ Blood grouping and Rh Typing
}

Other haematological investigation wherever necessary 
Volume - 10 | Issue - 11 | November - 2020 | PRINT ISSN No. 2249 - 555X | DOI : 10.36106/ijar

\section{Biochemical}

Blood urea

Blood sugar

Serum creatinine

\section{Microbiological}

HIV, HbSAg

\section{Radiological}

Plain X-Ray, Standing lumb/sacral spine AP and lateral views

Flexion and extention lateral view of lumbosacral spine

City scan and MRI scan lumbosacral spine

Chest X-ray PA view

Selection criteria for surgical interventions

Patients with failed conservative treatment

Positive straight leg raging test (SLRT)

Presence of leg and back pain

Neurogenic claudication pain

\section{Clinical Evaluation}

\section{Neurological evaluation}

There were no detritions of the neurological status of any patient either at the time of discharge from the hospital or at the final examination except two cases where patients developed foot drop post operatively. One patient had complete recovery and another one is undergoing recovery for which we applied foot drop splint. It was found that there was no correlation between the pedicle screw fixation and final neural status. 8 patients with Meyerding grade 2 improved to grade 1 and one patient of grade 3 improved to grade 2 and two patients with grade 1 had no improvement at all and remained grade 1. It was found that there is no correlation between the delay before surgery and the final neural status.

\section{Spinal deformity}

The clinical examination revealed that 10 patients had local Kyphotic deformity and only 2 patients with mild scoliosis. It is found that there is no significant correlation of the kyphotic deformity on post operative clinical examination

\section{Radiological Evaluation}

\section{Slip angle}

In our series we had 8 patients with slip angle $25^{\circ}-50^{\circ}$ and three patients with slip angle $0-25^{\circ}$ and one patients with slip angle of $50-75^{\circ}$ radiological evaluation was determined and initial examination, post operatively, and at final out patient follow-up.

1. The average pre operative slip angle was $35^{\circ}\left(0-75^{\circ}\right)$

2. The average post operative slip angle was $25^{\circ}\left(0-50^{\circ}\right)$

3 . The average slip angle at follow-up was $30^{\circ}\left(10-50^{\circ}\right)$

These results in an average gain in reduction of $10^{\circ}$ and an average lost at followup of $5^{\circ}$.

\section{Meyerding grading}

In our study, 8 cases are categorised into meyerding grade 11, 3 cases, Meyerding grade 1 and one case meyerding grade 3 on initial examination. Post operatively we had 9 cases of grade 1 and 3 cases grade 2 .

\section{Results for failure of implants}

In all cases we have done bone grafting procedure. Graft was taken from iliac crest of the patient. We did not attempt for reduction in all cases except one where we used reduction sews to attain reduction. All the cases have good intertransverse fusion. In one case we had the pedicle sews broken 6 months post operatively but due to solid intertransverse fusion the patients had consequence of symptoms.

\section{Radiological union}

All the cases on post operatively follow-up showed rigid intertransverse fusion

\section{Functional evaluation}

10 patients $(90 \%)$ were able to return to same work, $2(10 \%)$ were able to same work with some modification.

\section{ANALYSIS OF RESULTS}

Table 1. Sex Incidence

\begin{tabular}{|l|l|l|}
\hline Sex & Number $(\mathbf{N}=\mathbf{1 2})$ & \% \\
\hline Male & 10 & \\
\hline Female & 02 & \\
\hline
\end{tabular}

\section{Sex Incidence}

We have admitted 12 cases of spondylolisthesis out of which 2 are female and 10 are male. This incidence supports that degenraive spondylolisthesis is more common in female. (Table 1)

Table 2. Age incidence

\begin{tabular}{|l|l|l|}
\hline Age distribution & Number $(\mathbf{N}=12)$ & $\%$ \\
\hline $0-10$ & 0 & \\
\hline $10-20$ & 0 & \\
\hline $20-30$ & 0 & \\
\hline $30-40$ & 02 & \\
\hline $40-50$ & 08 & \\
\hline $50-60$ & 02 & \\
\hline
\end{tabular}

\section{Age incidence}

In our study, we have cases with age ranging from 35-60 yrs. The average age of presentation in 45 yrs (Table 2). All the patients have symptoms ranging from $<1$ to 4 yrs so the average age of symptomatic years is 2 yrs. (Table 4 )

Table 3. Levels of spondylolisthesis

\begin{tabular}{|l|l|l}
\hline Levels of spondylolisthesis & Number $(\mathbf{N}=12)$ & $\%$
\end{tabular}

\begin{tabular}{|l|l|l|}
\hline L5 & 10 & \\
\hline L4 & 02 & \\
\hline
\end{tabular}

Table 4. Time of surgery with respect to time of symptoms

\begin{tabular}{|l|l|l|}
\hline Time & Number $(\mathbf{N}=\mathbf{1 2})$ & $\%$ \\
\hline 1 year & 2 & \\
\hline 2 years & 4 & \\
\hline 3 years & 4 & \\
\hline 4 years & 2 & \\
\hline
\end{tabular}

\section{Functional status}

All the patients not able to perform their work preoperatively. Postoperatively there could return their same work or with some modifications.

\section{Meyerding grading}

In our study, we had 8 cases with meyerding grade 2, 3 cases with meyerding grade 1 and one case with meyerding grade 3 types initially. Postoperatively we had 6 cases of grade 2 with return to grade one and 2 cases remained grade 2 and 3 cases with grade 1 remained grade 1 with reduced displacement. One case of grade 3 return to grade 2 . (Table 5)

Table 5. Meyerding grading

\begin{tabular}{|l|l|l|}
\hline Meyerding & Number & \% \\
\hline Grade 1 & 3 & \\
\hline Grade 2 & 8 & \\
\hline Grade 3 & 1 & \\
\hline
\end{tabular}

\section{Slip angle}

In our study, we had patients slip angles ranging from $10-50^{\circ}$ with 8 cases having slip angles from $25-50^{\circ}$ and 3 cases having slip angles from $10-30^{\circ}$ and one case had $55^{\circ}$ slip angle initially. There was improvement in slip angle in 10 cases. Slip angles same as preoperative status in two cases. (Table 6 )

Average slip angle preoperative was $\left(100-55^{\circ}\right) 30^{\circ}$

Average post operative slip angle was $\left(5^{\circ}-45^{\circ}\right) 20^{\circ}$

Average slip angle at follow-up $25^{\circ}\left(10^{\circ}-50^{\circ}\right)$

This results in average gain in reduction of $5^{\circ}$ and average loss at follow-up of $5^{\circ}$

Table 6. Slip angle

\begin{tabular}{|l|l|l|}
\hline Slip angle & Number & $\%$ \\
\hline 300 (Pre Ope) & 8 & \\
\hline 200 (Post Ope) & 3 & \\
\hline 250 (Follow-up) & 1 & \\
\hline
\end{tabular}

\section{Neurological deficits}

We have no cases with preoperative neurological deficits in our study. In one case had we had foot drop in the post operative period with loss of sensation over dorsum of foot where the attempted reduction of listhesis. So in our study we had $10 \%$ neurological defects post operatively. 
decades. Increased sporting activities involving repetitive hyperextension are the main causes of condition. The concept of treatment of spondylolisthesis has been evolved from conservative measures like meditation, activities prescription and bracing dphysical therapy to open reduction and internal fixation with pedicle screw rod fixation and reduction of slippage. ${ }^{10-12}$ The goal of treatment of spondylolisthesis includes

- Reduction of slip to $50 \%$ or less but not necessarily to an anatomical position

- Effective decompression of spinal canal is necessary, achieved mostly with adequate reduction.

- Correlation of spinal deformity symptomatic, relief limitation of movement, instability, or pain

- Early mobilization and simplified nursing care

To acieve this goals surgery is the most convenient method for treatment of such condition. Management of spondylolithiosis is the one of the most controversial areas in modern spinal surgery. Early fusion with instrumentation is a generally accepted treatment method for patients with spondylolisthesis and a neurological deficit; it results in more rapid symptomatic relief, effective reduction of displacement, fewer complications, and lower medical cost.

The pedicle is the strongest part of the vertebra and is the force nucleus of the vertebral body. Through the pedicle all forces are transmitted from posterior elements to the spinal body, so it is very important in controlling motion transmitting force to the anterior spinal body. Therefore, by fixation of the vertebral body through the pedicle significant strength of the entire vertebral complex is possible. The pedicular fixation systems have the advantages that they are able to fix the three spinal columns and provide segmental stabilization for few spinal motion segments. ${ }^{14,15}$

In the treatment of spondylolisthesis, pedicle screws allow easy manipulation and reduction of displaced vertebrae, even if the posterior elements are not intact. Their use facilitates decompression of the neural elements by distraction, avoiding the need for laminectomy and permits stabilization of the segments without the requirement to extent fixation much behind the displaced vertebra. ${ }^{15}$ Moss Miami system acts posterior tension band based on intact anterior and posterior spinal ligaments and intact facetal joints acting as fulcrome in cases of burst fractures. Since in anterior spinal instrumentation such as Canada system involves more risk to the patients the posterior stabilization has become more popular as it involves indirect reduction and maintenance of stability of the spine. ${ }^{16}$

We had much favourable results using pedicle screw fixation and potserolateral fusion. We analysed the results in our 12 patients, 8 were females 2 were males. Age ranged from 35-60 yrs. Commonest involved level involved was L4 to L5 (Table 3). Degenerative (90\%) was the commonest in our study causing fixation injury with wedge compression and burst fractures and $40 \%$ was due to road traffic accidents.

There was an average pre-op slip angle of $30 \mathrm{o}$ of with maximum of $50^{\circ}$ and minimum of $20^{\circ}$ in our patients. Post operatively the average slip angle was $25^{\circ}$ reduced to an average of $30^{\circ}$. The slip angle was maintained the most of the cases with an average loss of correction of only $5^{\circ}$ in spite of doing an additional procedures of bone grafting, the maintenance of corrections is attributed mainly to the rigid cortical purchase of the pedicle screws and deferred mobilization on individual basis with lumbar brace.

We observed in less than $50^{\circ}$ slip angle loop 8 cases of meyerding grade 2 and 2 cases of meyerding grade 3 which improved to meyerding grade $1 \& 2$ respectively two cases of meyerding grade 1 remained grade 1 with correction of slip angle.

Our observation is that there are more number of meyerding grade 2 patients in the $<25^{\circ}$ than in other group and that the improvement neurological observed maximally in less than $25^{\circ}$ group. This is probably less severity nerve root compression initially. We could not obtain separate evidence in our literary search for this observation.

We reported screw breakage in one of the case which did not cause any neurological problem. Because of inter transverse fusion we did not plan for removal. We encountered foot drop in two cases post operatively in which one of the cases record and another is undergoing recovery. We applied foot drop splint in both cases. We had one case of CSF leakage intraoperatively which we repaired promptly and patient had no neurological problem.

Back pain is the most common. We had cases with the complaint of back pain which was not severe. No case had surgical site infection. One case has implant breakage in post operative period.

We planned for removal of screws but the patients did not turn up. Decompressive laminectomy was done for all cases where there was canal impingement by displaced vertebrae in no off patients.

We did bone grafting procedures in all our cases. We did not observe any aggravation of kyphosis in any of our patients. There was one breakage of implant in our study in the post operative period. Two cases had foot drop in the post operative period. We attempted reduction in one of these cases by reduction screws this complication is justified by the observation of Csécsei et al ${ }^{13}$ who described that the greatest danger to the L5 nerve root during the reduction Maneuver occurred during the last $25 \%$ of the reduction of slippage. Jacobs et al., 17 also reported the development of cauda equina syndromes after in situ fusion in 12 adolescents with grade 3 or grade 4 spondylolisthesis.

\section{CONCLUSION}

- Symptomatic spondylolisthesis in adults improve with mossmiami pedicle screw rod system

- Patients can be ambulated early

- Intertransverse fusion process with stabilization of the motion segment with moss-miami is very successful in relieving symptoms of the patient.

\section{ACKNOWLEDGMENT}

The author thankful to Department of orthopaedics for providing all the facilities to carry out this work.

\section{CONFLICT OF INTEREST}

\section{None}

\section{REFERENCES}

1. Feffer, H.L., Wiesel, S.W., Cuckler, J.M. and Rothman, R.H. (1985) Degenerative Spondylolisthesis. To Fuse or Not to Fuse. Spine, 10, 287-289. http:// dx. doi. org/ 10. 1097/00007632-198504000-00018

2. Fuji, T., Oda, T., Kato, Y., Fujita, S. and Tanaka, M. (2003) Posterior Lumbar Interbody Fusion Using Titanium Cylindrical Threaded Cages: Is Optimal Interbody Fusion Possible without Other Instrumentation? Journal of Orthopaedicscience:Official Journal of the Japanese Orthopaedic Association, 8, 142-147.http:// dx. doi. org/ 10. Journal of the Japanes

3. Idowu, O.E., Adewole, O.A. and Majekodunmi, A.A. (2012) Posterior Spinal Decompression, Stabilization and Arthrodesis in Nigerian Adults: Profile and Outcome. Nigerian Medical Journal: Journal of the Nigeria Medical Association, 53, 42-46. http://dx.doi.org/10.4103/0300-1652.99832

4. Janssen, M.E., Lam, C. and Beckham, R. (2001) Outcomes of Allogenic Cages in Anterior and Posterior Lumbar Interbody Fusion. European Spine Journal: Official Publication of the European Spine Society, the European Spinal Deformity Society, and the European Section of the Cervical Spine Research Society, 10, S158-S168.

5. Agazzi, S., Reverdin, A. and May, D. (1999) Posterior Lumbar Interbody Fusion with Cages: An Independent Review of 71 Cases. Journal of Neurosurgery, 91, 186-192. http://dx.doi.org/10.3171/spi.1999.91.2.0186

6. Burkus, J.K., Dorchak, J.D. and Sanders, D.L. (2003) Radiographic Assessment of Interbody Fusion Using RecombinantHuman Bone Morphogenetic Protein Type 2. Spine, 28,372-377.http://dx.doi.org/10.1097/01.BRS.0000048469.45035.B9.

7. Chitnavis, B., Barbagallo, G., Selway, R., Dardis, R., Hussain, A. and Gullan, R. (2001) Posterior Lumbar InterbodyFusion for Revision Disc Surgery: Review of 50 Cases in Which Carbon Fiber Cages Were Implanted. Journal ofNeurosurgery, 95, 190195.http://dx.doi.org/10.3171/spi.2001.95.2.0190.

8. Sasso, R.C., LeHuec, J.C., Shaffrey, C. and The Spine Interbody Research Group (2005) Iliac Crest Bone Graft DonorSite Pain after Anterior Lumbar Interbody Fusion: A Prospective Patient Satisfaction Outcome Assessment. Journal ofSpinal Disorders \& Techniques, 18, S77-S81. http://dx.doi.org/10.1097/01.bsd.0000112045.36255.83.

9. Carreon, L.Y., Puno, R.M., Dimar, J.R., Glassman, S.D. and Johnson, J.R. (2003) Perioperative Complications ofPosterior Lumbar Decompression and Arthrodesis in Perioperative Complications of Posterior Lumbar Decompression and Arthrodesis in
Older Adults. The Journal of Bone and Joint Surgery (AmericanVolume), 85-A, 20892092.
Cho, K

10. Cho, K.-J., Suk, S.-I., Park, S.-R., et al. (2008) Short Fusion versus Long Fusion for Degenerative Lumbar Scoliosis.European Spine Journal, 17, 650-656. http:// dx. doi. org/10.1007/s00586-008-0615-Z

11. Zhang, Q.H. and Teo, E.C. (2008) Finite Element Application in Implant Research for Treatment of Lumbar DegenerativeDisc Disease. Medical Engineering \& Physics, 30 , 1246-1256.http://dx.doi.org/10.1016/j.medengphy.2008.07.012.

12. Brantigan, J.W., Steffee, A.D., Lewis, M.L., Quinn, L.M. and Persenaire, J.M. (2000) Lumbar Interbody Fusion Usingthe Brantigan I/F Cage for Posterior Lumbar Interbody Fusion and the Variable Pedicle Screw Placement System:Two-Year Results from a Food and Drug Administration Investigational Device Exemption Clinical Trial. Spine, 25,1437-1446. http://dx.doi.org/10.1097/00007632-200006010-00017.

13. Csécsei, G.I., Klekner, A.P., Dobai, J., Lajgut, A. and Sikula, J. (2000) Posterior Interbody Fusion Using LaminectomyBone and Transpedicular Screw Fixation in the Treatment of Lumbar Spondylolisthesis. Surgical Neurology, 53, 2-6; Discussion 6. http://dx.doi.org/10.1016/S0090-3019(99)00198-6

14. Panjabi, M.M. (1988) Biomechanical Evaluation of Spinal Fixation Devices: I. A Conceptual Framework. Spine, 13, 1129-1134. http://dx.doi.org/10.1097/00007632- 
15. Ganju, A. (2002) Isthmic Spondylolisthesis. Neurosurgical Focus, 13, 1-6. http:// dx.doi. org/10.3171/foc.2002.13.1.2

16. Fraser, R.D. (1995) Interbody, Posterior, and Combined Lumbar Fusions. Spine, 20, 167S-177S.http://dx.doi.org/10.1097/00007632-199512151-00016

17. Jacobs, W.C.H., Vreeling, A. and De Kleuver, M. (2006) Fusion for Low-Grade Adult Isthmic Spondylolisthesis: ASystematic Review of the Literature. European Spine Isthmic Spondylolisthesis: ASystematic Review of the Literature.
Journal, 15,391-402.http://dx.doi.org/10.1007/s00586-005-1021-4 